\title{
New materials in old niches
}

Martin R. Bryce

\author{
Advanced Materials for Optics and Electronics. Editor-in-chief D. J. Cole-Hamilton. \\ Wiley. 6/yr. \$595 (institutional); $\$ 445$ (personal). \\ Molecular Engineering. Editors J.-M. Lehn, J. Maruani and J. Zyss. Kluwer. 4/yr. \\ DFL382. \\ Molecular Materials. Editor-in-chief L. M. Blinov. Gordon and Breach. 4/yr. \$384 \\ (institutional); \$85, £57 (personal).
}

CONTEMPORARY materials science crosses the traditional boundaries of biology, chemistry, physics and engineering. Each of these three new journals is aimed at a multidisciplinary readership, with something for anyone interested in the synthesis, characterization and device applications of molecular or polymeric materials. The unifying theme of the journals is that the materials discussed should possess specific properties (biological, chemical or physical) related to the burgeoning discipline of information technology. In the issues that I surveyed, papers cover a wide range of topics such as liquid crystals, evaporated thin films, Langmuir-Blodgett films, charge-transfer interactions, nonlinear optics, ferroelectrics, laser dyes and processing of device structures. The new journals will have to compete not only with one another but also with established interdisciplinary materials publications such as Advanced Materials, Chemistry of Materials, Journal of Materials Chemistry and Macromolecules, all of which surpass the new publications both in the quality of science reported and in the layout of the articles. From the viewpoint of a chemist, I fail to see the justification for even one new materials journal, let alone three. Many of the articles in my own area of knowledge were of mediocre quality, reporting results that were largely routine. There were, however, a few refreshing exceptions.

Advanced Materials for Optics and Electronics has been created by combining Chemtronics and Molecular Electronics. The subject matter is divided roughly equally between organic and inorganic materials, with an emphasis on physical characterization, spectroscopy and engineering studies. Each issue contains, on average, six original research papers, which makes it a very expensive publication. There is scope to publish short communications, but there were no such pieces in the issues I looked at. The average time between acceptance of the manuscript and publication is three to four months. Colour figures are used to good effect in some articles.

Molecular Engineering is published only four times a year, which will inevitably lead to some delays in publication. The review articles and research papers are concerned with both experimental and theoretical studies, with an emphasis on organic and bioorganic systems, including membranes. Several papers concern semiempirical studies. The presentation is variable: more than one paper contained several typographical errors and, incredibly, there were even handwritten chemical formulae and (badly) hand-drawn spectra.

Molecular Materials forms Section C of Molecular Crystals and Liquid Crystals Science and Technology. All the members of the editorial board originate from Russia and former Soviet territories, which seems to contradict one of the stated aims of the journal, which is to attract "molecular materials scientists interested in

\section{German parochialism}

\section{Athene M. Donald}

Acta Polymerica. Editors M. Ballauff, G. Hinrichsen, B. Philipp, A.-D. Schlüter, H.-W. Spiess and H. G. Zachmann. $V C H$. 6/yr. DM498, £183, \$360 (institutional); DM150, £57, \$125 (personal).

THIs journal is not strictly new. It has appeared under the same name for 40 years as a journal of the East German Academy of Sciences, but has recently been redirected with the aim of serving and reaching the wider community outside the former Eastern bloc. I do not believe the transformation is yet complete, and so the judgement passed here should perhaps still be regarded as provisional.

The primary authors of almost all the papers are, however, still German (although now from all parts) and the former Communist countries. The only papers from the United States that I have spotted, for instance, are from two members of the international advisory board. It is too early to tell whether the journal will succeed in overcoming this hurdle, but unless it does it is hard to see how it will gain credibility in its new role. Its coverage is not specific — "for researchers in all fields of polymer science" and "emphasizing an interdisciplinary approach, giving priority to the international collaborations which are developing". Most of the manuscripts are from ex-Soviet laboratories. Are the papers being refereed exclusively from within ex-Soviet territories? If so, this is an unhealthy situation that is unlikely to attract manuscripts from around the world. We are all benefiting from the increased availability of reports of good-quality research in the former Soviet Union in our libraries, and this journal may assist the contributors in gaining international recognition for their work; but I am concerned that in the reference sections of many of the papers there is an overemphasis on citations from Russian journals that will be difficult to locate in the West. I am also aware of key references in Western journals that have been overlooked.

New materials, in all shapes, sizes and forms, are set to remain at the forefront of research for at least the next decade, so these new journals may survive, but at present they are not attracting any seminal publications or carving out any new niches.

Martin R. Bryce is in the Department of Chemistry, University of Durham, Durham DH1 3LE, UK. physics and physical chemistry of polymers". It is not alone in hoping to do this, and the well established journal Polymer is an obvious rival in this area.

Publication time seems reasonable at around six months. But part of this relative rapidity is due to the fact that most papers are accepted as submitted, with a paltry minority indicating a date for receipt of a revised manuscript. The speed does not adequately reflect the quality of the papers, which largely seem to be worthy rather than cutting-edge. The production is adequate, although for photographs the matt quality of printing is less than desirable.

As it stands, I cannot see this journal cutting much of a swathe on the international scene. There are already highly respected journals on polymer science out there. There is a need for crossfertilization between Eastern Europe and the West and it is possible that in time the journal will achieve this. Its price is in its favour, low enough for individuals to be tempted to subscribe in order to keep a watching brief on pan-German science, which for now is basically all they will be getting.

Athene M. Donald is in the Cavendish Laboratory, University of Cambridge, Madingley Road, Cambridge CB3 OHE, UK. 